\title{
Alveolar Artery
}

National Cancer Institute

\section{Source}

National Cancer Institute. Alveolar Artery. NCI Thesaurus. Code C52848.

A branch of the maxillary artery that is found in the gingiva, premolars, and molars. 